\title{
Systems Epidemiology: A New Direction in Nutrition and Metabolic Disease Research
}

\author{
Marilyn C. Cornelis • Frank B. Hu
}

Published online: 3 September 2013

(C) Springer Science+Business Media New York 2013

\begin{abstract}
Systems epidemiology applied to the field of nutrition has potential to provide new insight into underlying mechanisms and ways to study the health effects of specific foods more comprehensively. Human intervention and populationbased studies have identified i) common genetic factors associated with several nutrition-related traits and ii) dietary factors altering the expression of genes and levels of proteins and metabolites related to inflammation, lipid metabolism, and/or gut microbial metabolism, results of high relevance to metabolic disease. System-level tools applied type 2 diabetes and related conditions have revealed new pathways that are potentially modified by diet and thus offer additional opportunities for nutritional investigations. Moving forward, harnessing the resources of existing large, prospective studies within which biological samples have been archived and diet and lifestyle have been measured repeatedly within individuals will enable systems-level data to be integrated, the outcome of which will be improved personalized optimal nutrition for prevention and treatment of disease.
\end{abstract}

Keywords Nutrition - Systems · Genomics ·

Transcriptomics $\cdot$ Proteomics $\cdot$ Metabolomics $\cdot$ Type 2

diabetes $\cdot$ Obesity $\cdot$ Metabolic disease $\cdot$ Epidemiology

Populations · Diet · Network · Nutrigenetics · Nutrigenomics

\section{Introduction}

Traditional epidemiology has made important contributions to the identification of many key lifestyle and environmental risk factors for chronic disease. Technical advances that now allow

M. C. Cornelis • F. B. Hu

Department of Nutrition, Harvard School of Public Health, Boston, MA, USA

\section{F. B. $\mathrm{Hu}(\bowtie)$}

Depts. of Nutrition and Epidemiology, Harvard School of Public Health, 665 Huntington Avenue, Boston, MA 02067, USA

e-mail: Frank.hu@channing.harvard.edu high-throughput measurements of genomic, transcriptomic, proteomic, and metabolomic traits in combination with more sophisticated bioinformatics and statistical methods provide epidemiologists an unprecedented opportunity to unlock the full potential of their research approach. "Systems Epidemiology" couples traditional epidemiologic methods with modern highthroughput technologies to enhance biological understanding of metabolic pathways in humans [1-4]. Nutrition research is a potentially ideal field for the application of systems approaches [5]. The dietary record and food frequency questionnaire have been instrumental to developing knowledge of the role diet plays in population health. However, these tools along with other aspects of epidemiological methods have well-known limitations that impede further advancements in the human nutrition field. Foods are mixtures of known and unknown constituents, and separating as well as characterizing the effects each in the context of individual intrinsic variances is an ongoing challenge in classical nutritional epidemiology.

The purpose of this review is to provide an overview of systems epidemiology with application to nutrition. We discuss progress in applying system-level tools to the study of both type 2 diabetes (T2D) and nutrition. Results of each highlight important connections between them and underscore the great potential for systems epidemiology in advancing nutrition research for disease prevention.

\section{System Level I: Human Genome}

Enthusiasm for systems epidemiology is fueled, in part, by the marked recent successes in human genomics: the study of an individual's entire gene set, including gene-gene and geneenvironment interactions. Genome-wide association studies (GWAS) of T2D have contributed to the identification of approximately 65 susceptibility loci [6••], which is an astounding improvement upon the small handful of loci described preGWAS [7]. Genome-wide analytical approaches also have proven successful for a number of important nutrition-related traits (Table 1). For example, single nucleotide polymorphisms 
Table 1 Genome-wide significant loci associated with nutrition-related traits ${ }^{1}$

\begin{tabular}{|c|c|c|c|}
\hline Trait & Locus $^{2}$ & Genes in region & Ref \\
\hline \multicolumn{4}{|l|}{ Plasma amino acids } \\
\hline \multirow[t]{2}{*}{$\begin{array}{l}\text { Alanine, isoleucine } \\
\text { Glutamine }\end{array}$} & $\begin{array}{l}2 \mathrm{p} 24 \\
10 \mathrm{q} 24\end{array}$ & $\begin{array}{l}\text { GCKR, SNX17, PMG1, NRBP,FNDC4 } \\
\text { HOGA1, MORN4 }\end{array}$ & \multirow[t]{6}{*}{ [135] } \\
\hline & $12 q 13$ & TIMELESS, MIP, SPRYD4, GLS2, BAZ2A & \\
\hline $\begin{array}{l}\text { Histidine } \\
\text { Phenylalanine }\end{array}$ & $\begin{array}{l}4 \mathrm{q} 35 \\
5 \mathrm{q} 33-\mathrm{q} 35\end{array}$ & $\begin{array}{l}\text { CYP4V2, KLKB1, F11 } \\
\text { F12, GRK6 }\end{array}$ & \\
\hline Tyrosine & $16 \mathrm{q} 22$ & $\begin{array}{l}\text { CHST4, TAT, PHLPPL, MARVELD3, AP1G, } \\
\text { SNORD71, ZNF821, PKD1L3 }\end{array}$ & \\
\hline \multirow[t]{2}{*}{ Valine } & $2 \mathrm{p} 15-\mathrm{p} 13$ & SLC1A4 & \\
\hline & $4 \mathrm{q} 22$ & PPMIK, HERC6, ABCG2 & \\
\hline Betaine & $\begin{array}{l}12 \mathrm{p} 13.33 \\
5 \mathrm{q} 14.1\end{array}$ & $\begin{array}{l}\text { SLC6A12, SLC6A13 } \\
\text { BHMT, BHMT2, DMGDH }\end{array}$ & \multirow[t]{3}{*}[136]{} \\
\hline Glycine & $2 q 34$ & CPS1 & \\
\hline Serine & $1 \mathrm{p} 12$ & PHGDH & \\
\hline \multicolumn{4}{|l|}{ Plasma fatty acids } \\
\hline $\begin{array}{l}\text { Linoleic acid, omega-3 FA } \\
\text { Linoleic acid omega- } 6 \text { \& omega-7 FA }\end{array}$ & $\begin{array}{l}11 \mathrm{q} 12-\mathrm{q} 13 \\
11 \mathrm{q} 23\end{array}$ & $\begin{array}{l}\text { MYRF, FEN1, FADS(1-3), DAGLA, BEST, FTH1 } \\
\text { BUD13, ZNF259, APOA5, APOA4 }\end{array}$ & \multirow[t]{5}{*}{ [135] } \\
\hline & $1 \mathrm{p} 31.3$ & DOCK7, ANGPTL3 & \\
\hline $\begin{array}{l}\text { Linoleic acid, omega- } 6 \text { \& omega-7 FA, } \\
\text { omega-9 \& saturated FA, other PUFA than linoleic }\end{array}$ & $15 q 21-q 23$ & LIPC, ADAMIO & \\
\hline Omega-9 \& saturated FA & $2 \mathrm{p} 24$ & GCKR, SNX17, PMG1, NRBP1, FNDC4, & \\
\hline Other PUFA than linoleic & $11 \mathrm{q} 12$ & $C D 6, C D 5, V P S 37 C, P G A 3$ & \\
\hline \multicolumn{4}{|l|}{ Plasma vitamins \& minerals } \\
\hline Beta-carotene & $16 \mathrm{q} 23.2$ & PKD1L2, BCMO1 & {$[137]$} \\
\hline Calcium & $3 \mathrm{q} 21.1$ & CASR,CSTA,WDR5B,KPNA1,CCDC58 & {$[138,139]$} \\
\hline $\begin{array}{l}\text { Carbohydrate-deficient transferrin (and \%), transferrin, } \\
\text { total iron binding capacity }\end{array}$ & $3 q 22.1$ & $T F, S R P R B$ & [140-143] \\
\hline Carbohydrate-deficient transferrin (\%) & $1 \mathrm{p} 31$ & $P G M 1, R P L 19 P 3$ & {$[140]$} \\
\hline $\begin{array}{l}\text { Erythrocyte mean cell volume, iron-soluble transferrin } \\
\text { receptor }\end{array}$ & $22 q 12.3$ & TMPRSS6 & {$[143-146]$} \\
\hline $\begin{array}{l}\text { Erythrocyte mean cell volume, ferritin, iron, soluble } \\
\text { transferrin receptor, transferrin, transferrin saturation, } \\
\text { unsaturated iron binding capacity, total iron } \\
\text { binding capacity }\end{array}$ & $6 \mathrm{p} 21.3$ & $H F E$ & {$[140-144,146]$} \\
\hline Ferritin & $6 \mathrm{p} 22.2$ & SLC17A1 & [143] \\
\hline Soluble transferrin receptor & $\begin{array}{l}11 \mathrm{q} 23 \\
11 \mathrm{q} 23.3\end{array}$ & $\begin{array}{l}\text { BUD13, ZNF259, APOA5, APOA4 } \\
\text { PCSK7 }\end{array}$ & {$[146]$} \\
\hline Transferrin saturation & $6 \mathrm{p} 22.1$ & HIST1H2BJ, VN1R13P, VN1R11P & {$[142]$} \\
\hline \multirow[t]{5}{*}{ Magnesium } & $\begin{array}{l}11 \mathrm{p} 14.1 \\
12 \mathrm{q} 21.33\end{array}$ & $\begin{array}{l}D C D C 5, M P P E D 2 \\
A T P 2 B 1, M R P L 2 P 1\end{array}$ & \multirow[t]{5}{*}[147]{} \\
\hline & $1 \mathrm{q} 22$ & MUC1 & \\
\hline & $3 q 26.2$ & MDS1, MECOM & \\
\hline & $4 \mathrm{q} 21.1$ & SHROOM3 & \\
\hline & $9 \mathrm{q} 21.13$ & TRPM6 & \\
\hline Retinol & $\begin{array}{l}10 \mathrm{q} 23.33 \\
18 \mathrm{q} 12.1\end{array}$ & $\begin{array}{l}\text { RBP4, FFAR4 } \\
\text { TTR,B4GALT6 }\end{array}$ & [148] \\
\hline \multirow[t]{4}{*}{ Vitamin B12 } & $\begin{array}{l}11 \mathrm{q} 12.1 \\
13 \mathrm{q} 32.3\end{array}$ & $\begin{array}{l}M S 4 A 3 \\
C L Y B L\end{array}$ & \multirow[t]{4}{*}{ [149-151] } \\
\hline & $19 \mathrm{p} 13.3$ & FUT6 & \\
\hline & $19 q 13.33$ & FUT2 & \\
\hline & $5 q 32$ & ASS1P10, PRELID2 & \\
\hline
\end{tabular}


Table 1 (continued)

\begin{tabular}{|c|c|c|c|}
\hline Trait & Locus $^{2}$ & Genes in region & Ref \\
\hline Vitamin B6 & $1 \mathrm{p} 36.12$ & $A L P L, N B P F 3$ & {$[150]$} \\
\hline \multirow[t]{2}{*}{ Vitamin D (and insufficiency) } & $\begin{array}{l}11 \mathrm{p} 15.2 \\
11 \mathrm{q} 13.4\end{array}$ & $\begin{array}{l}\text { CYP2R1 } \\
\text { NADSYN1,DHCR7 }\end{array}$ & \multirow[t]{2}{*}[152-154]{} \\
\hline & $4 \mathrm{q} 13.3$ & $G C$ & \\
\hline $\begin{array}{l}\text { Alpha-tocopherol, vitamin E response to vitamin E } \\
\text { supplementation }\end{array}$ & $11 \mathrm{q} 23$ & BUD13, ZNF259, APOA5, APOA4 & {$[137,155,156]$} \\
\hline \multirow[t]{2}{*}{ Vitamin E } & $12 \mathrm{q} 24.31$ & SCARB1 & \multirow[t]{2}{*}[156]{} \\
\hline & $19 \mathrm{p} 13.12$ & $C Y P 4 F 2$ & \\
\hline \multicolumn{4}{|l|}{ Dietary behaviors } \\
\hline Habitual alcohol consumption & $\begin{array}{l}12 \mathrm{q} 24.11-13 \\
7 \mathrm{q} 11.22\end{array}$ & $\begin{array}{l}\text { CCDC63, MYL2, ALDH2, BRAP, CUX2, } \\
\text { AUTS2 }\end{array}$ & {$[157-160]$} \\
\hline $\begin{array}{l}\text { Habitual caffeine consumption, habitual coffee } \\
\text { consumption }\end{array}$ & $\begin{array}{l}7 \mathrm{p} 21 \\
15 \mathrm{q} 24.1\end{array}$ & $\begin{array}{l}A H R \\
L M A N 1 L, E D C 3, C Y P 1 A 2, C Y P 1 A 1, C S K\end{array}$ & {$[20,161,162]$} \\
\hline Habitual protein consumption & $19 q 13.33$ & FGF21, FUT1, FUT2, IZUMO1, RASIP1 & {$[163]$} \\
\hline
\end{tabular}

(SNPs) have been associated with variation in plasma levels of iron and omega- 3 fatty acids and consumption of dietary protein, alcohol, and coffee, all of which are dietary factors implicated in T2D [8-13]. Knowledge of the genetic determinants of diet response or behavior may provide insight into underlying mechanisms and ways to study the potential health effects of diet more comprehensively by using genetic determinants as instrumental variables or by taking into consideration gene-diet interactions. Other products of the GWAS era, besides the newly identified variants, such as consortium and innovative statistical design, have greatly advanced the way such investigations are currently being conducted. Recent work aiming to confirm or refute causal effects and/or gene-environment interactions has involved cohort collections that are far larger than those utilized in the pre-GWAS era; this work has been facilitated by advanced meta-analysis techniques to combine data, and/or the availability of extensive replication materials [14, $15 \cdot, 16,17]$. The majority of published GWAS have reported on disease-associated loci, but more recently GWAS has been extended to examine variation in nutrient-response or behavior. Adverse effects of several established T2D-associated loci may be attenuated by adopting healthy lifestyle behaviors, such as high physical activity, whereas low physical activity and a Western dietary pattern have been found to augment genetic risk [15•]. In a recent study among three independent cohorts of adults predisposed to obesity by virtue of a high genetic score of established obesity risk loci, the genetic effects were significantly more pronounced in those who consumed high quantities of sugar-sweetened beverages compared with those who did not $[18 \bullet \bullet$.

The currently known susceptibility loci for T2D explain only $5-10 \%$ of the previously estimated heritability of the disease $[6 \cdot \bullet]$ and add only modestly to traditional disease risk factors in prediction models [19॰]. Likewise, SNPs associated with dietary behaviors explain very little of the trait variance and/or heritability [20]. This partly reflects the complexity of behaviors and metabolic disease, which is further compounded by measurement error ascribed to their assessment within- and between populations [21]. Knowledge gleaned by other system-level data may greatly facilitate continued progress in these areas of human genomics.

\section{System Level II: Human Transcriptome}

The transcriptome is the complete set of messenger RNA molecules in a cell or a tissue at a given time. Unlike the genome, which changes very little during a person's lifetime, the transcriptome (as well as the proteome and metabolome) can vary by developmental stage and environment [22]. Because transcript quantification requires sufficient volumes of high-quality homogenous cellular material, human studies often are restricted to biopsies from accessible tissues, such as subcutaneous adipose tissue, skeletal muscle, and peripheral blood mononuclear cells [23]. Blood is the most feasibly collected in a population setting, but its use in gene expression 
assumes that it provides general information on transcription in different cells and tissues, including those more relevant for the phenotype or disease of interest. GW expression studies of T2D have been predominately small, cross-sectional by design, and without replication [24]. Only recently has the approach been applied to incident T2D: a GW screen of miRNAs in the Bruneck cohort revealed a plasma miRNA signature for incident T2D that includes loss of endothelial miR-126 [25]. The latter plays a pivotal role in maintaining endothelial homeostasis and vascular integrity [26].

Numerous human intervention studies have used transcriptomics to characterize molecular response to dietary factors such as dietary fatty acids [27-31], carbohydrates [32], probiotics [33], folic acid [34], olive oil [27, 35], creatine monohydrate [36], vitamin E and selenium [37], CoQ10 [38], soy isoflavones [39], and different diets [40-44]. Most reveal significant yet subtle changes in transcript levels. Convincing human evidence suggests that many of the biological effects of unsaturated fatty acids are mediated through modulation of gene transcription by regulating the activity of transcription factors, such as peroxisome proliferator-activated receptors, retinoid $\mathrm{X}$ receptor, liver $\mathrm{X}$ receptor, and sterol regulatory binding proteins [23]. In light of emerging data showing gut flora compositions (or "microbiota") differ between healthy individuals and diabetics or obese [45-47], results from gene expression measures of duodenal mucosa following supplementation of Lactobacillus GG are encouraging. Lactobacillus GG, also found in yogurt and other fermented foods, altered the expression of genes involved in immune response and inflammation, apoptosis, cell growth and cell differentiation, cell-cell signaling, cell adhesion, and signal transcription, and transduction [33].

Altered transcript levels in response to diet can inform mechanisms of action but whether such changes observed in nutritional intervention studies have relevance to a population setting and/or are large enough to have any impact on disease development is an open question. Little is known about whether or how specific dietary factors induce changes in gene expression of disease target tissue. To acquire such knowledge our only feasible option might be to complement human data with that obtained from experimental models. Genome-wide expression profiles collected from mouse liver and adipose tissue are notably enriched for altered transcripts of immunity-related genes when their high fat diets are supplemented with coffee [48]. Coffee suppressed expression of liver cytokine interleukin (IL)-1 $\beta$ and MCP-1 gene expression in white adipose tissue [48]. Given the role inflammation may have in development of T2D [49], these observations suggest a relevant mechanism by which coffee might reduces risk of the disease in humans. Nearly all GW scale studies concerning diet-induced changes in gene expression of pancreatic $\beta$-cells, a key target tissue for $\mathrm{T} 2 \mathrm{D}$, originate from rodent animal models or cultured cell lines [50•]. While offering insight to tissue-specific gene-expression not easily obtained from humans, experimental studies are not without limitations and will warrant caution when translating to humans.

\section{System Level III: Human Proteome}

Transcript levels do not always correspond to protein levels, stressing the need to study proteins directly. The proteome may contain over a million structurally different proteins performing distinct functions in an individual and the goal of proteomics is to simultaneously quantify these proteins in biological samples $[51,52]$. Currently, no single analytical platform is able to capture the full spectrum of proteins; those present at low concentrations and abundance are especially difficult to detect and characterize [53]. Metabolic diseases, such as diabetes, involve various affected tissue and because all are in contact with blood, tissue-specific proteins with diagnostic potential might be recovered in the circulation [52]. Blood is therefore an attractive biospecimen for protein profiling in population settings but also is the most complex to study [52]. Many individual serum proteins, such as interleukin-6, resistan, leptin, and adiponectin, have been shown to vary between healthy and insulin-resistant (IR) or diabetic individuals [54-57], lending some support to the potential for global protein profiling. Indeed, the few small-scale studies that have applied proteomics have revealed potentially novel biomarkers of IR or T2D [58]. These include blood circulating flotillin-1, arginase, syntaxin $1 \mathrm{C}$, haptoglobin, and complement C3 [59, 60]; mitochondrial, cytoskeletal, proteasome, and chaperone proteins in skeletal muscle [61]; and structural and stress/unfolded protein response proteins in subcutaneous adipose tissue [62]. Proteomics applied to human nutritional intervention studies have ranged from 1 to 12 weeks in duration and have, for example, tested soy isoflavones [63], flaxseed [64], fish oil [65], folic acid [66], and anti-inflammatory mixtures [67]. Serum levels of inflammatory and lipid proteins, such as APOA1, zinc-a-2-glycoprotein, haptoglobin precursor, amyloid $\mathrm{P}$ component, and hemopexin, are down-regulated by 6 weeks of fish oil compared with sunflower oil supplementation [65]. Following 8 weeks of $25 \mathrm{mg}$ of isoflavone supplementation, blood cell levels of proteins promoting fibrinolysis (i.e., alpha-enolase) were higher, whereas those mediating adhesion, migration, and proliferation of vascular smooth muscle cells (i.e., galectin-1) were lower [63].

Thus far, proteomics has had limited application to population studies of human metabolic disease or nutrition. To our knowledge, no prospective proteomic studies of T2D have been conducted, and the few population-based studies of nutritional factors have been small and have all targeted $<60$ proteins [68-71], most of which are from the inflammatory and/or oxidative stress classes of proteins. However, with continued advancements in the field, such as high-throughput tools for the fractionation of biological samples and growing 
databases housing tissue-specific protein reference maps, this pattern promises to change in the near future.

\section{Systems Level IV: Human Metabolome}

Metabolomics involves the comprehensive analysis of all measurable metabolite concentrations under a given set of conditions $[72,73]$. These metabolites are the final products of preceding "omic" processes and their interaction with intrinsic and extrinsic factors [72, 73]. Thus far, more than 37,000 unique metabolites have been identified in human specimens $[74,75]$ (http://www.hmdb.ca, accessed June 2013). Similar to the proteome, no single analytical platform captures the full spectrum of metabolites. Analyses can be conducted in an untargeted manner, typically optimized for broad coverage of the metabolome to enhance opportunities of discovering discriminatory features of a disease/trait, or in a targeted manner, profiling only a defined set of known metabolites to enable improved sensitivity and efficiency [76]. Metabolomics is increasingly applied in the clinical and population setting. Detailed technological and conceptual challenges as well as progress in the broader field have been discussed elsewhere [77•].

Recent metabolomic studies of T2D have considerably improved upon the earlier cross-sectional reports [78, 79]. Among adult population-based studies involving up to 800 incident cases, targeted metabolite profiling has identified an array of novel metabolite classes linked to T2D onset, such as short- and medium-chain acylcarnitines, the specific lipid classes of sphingomyelins (SMs), lysophosphatidylcholines, phosphatidylcholines (PCs), and lysophosphatidylethanolamines, and branched-chain amino acids (BCAAs) [80, 81, $82 \bullet \bullet, 83,84]$. Some of these classes also have been linked to obesity and other T2D-related traits [85-90]. Patterns linked with T2D among adults have not always been replicated in younger populations [91, 92], supporting the need for longitudinal monitoring to enable trajectory analysis of metabolic responses. Further work is needed to determine whether these metabolites are elevated because of an individual's genetic or diet characteristics, and/or the actions of gut microbes [93]. Interestingly, high dietary protein intake is associated with T2D and higher plasma levels of BCAAs [8, 94]. PCs occur in animal and plant tissues and are therefore present in the diet (e.g., eggs and soy beans). Recent work suggests these phospholipids are further metabolized by intestinal microbiota, producing the proatherosclerotic metabolite trimethylamineN-oxide [95, 96••, 97, 98].

Metabolomics has been used to characterize the complex human metabolic effects of specific foods, nutrients, and dietary patterns in both the clinical and population setting [99, 100, 101, 102-107]. Intervention studies of coffee [108-111], tea $[112,113]$, cocoa [114, 115], nuts [116], dietary fiber [117], vitamins and selected nutraceuticals $[67,118]$, for example, have incorporated either targeted or untargeted metabolite profiling. Earlier reports have favored the presentation of exogenously derived metabolites. Confirmed metabolite markers of coffee exposure, for example, include mainly methylxanthines and reduced, sulfated, and methylated forms of hydroxycinnamates [108-111], which are coffee-derived metabolites. There is, however, an increasing interest in the impact foods have on the endogenous metabolome (known as the "host response") [115]. Potential markers of nut intake include conjugated fatty acids, serotonin metabolites, and microbial-derived phenolic metabolites [116]. Metabolites linked with carnitine metabolism, sulfation of tyrosine, and gut microbial metabolism are among the set of metabolites linked to cocoa intake [115]. Evidence for diet-induced altered intestinal microbiota metabolism is particularly relevant in light of results from metabolomic studies of T2D and other system-level results discussed above.

Population-based studies designed to identify metabolite signatures of self-reported dietary intake have targeted a similar set of metabolites to that of recent metabolomic studies of T2D (i.e., lipids, amino acids and their derivatives). In a population sample of men, coffee intake was positively associated with specific classes of SMs and negatively associated with long- and medium-chain acylcarnitines in plasma [119], classes previously linked to reduced and increased risk of T2D, respectively [80, 81, 120-122]. The negative association between coffee and medium-chain acylcarnitines was later confirmed in an independent study of women from the TwinsUK cohort [123], which additionally identified metabolites associated with garlic, fruit, and vegetable intake and hypocaloric dieting [123]. Of relevance to the utility and interpretation of metabolomic approaches applied to populations is recent work by Heinzmann et al. [124•] and Krug et al. [101•], showing that interindividual metabolic differences influence proportionally more of the spectrum of metabolites than dietary modulation, although certain individuals display a greater stability of metabolic phenotypes than others $[101 \bullet, 124 \bullet]$. Some of this stability is likely heritable; in the TwinsUK study mentioned above, two thirds of the metabolites associated with nutritional patterns had a significant genetic contribution, and the remaining third were solely environmentally determined [123].

Metabolomics has already provided new insight to chronic disease development and response to diet. Its application in a population setting might further enable epidemiologists to separate metabolites resulting from inherited patterns of metabolism from those that are entirely due to environment [123]. This particular task will greatly benefit from findings of other system-level analysis, the most apparent being genomics. Indeed, several GW-confirmed loci are associated with variation in plasma levels of metabolites implicated in T2D and additionally influenced by diet (Table 1) [125]. Recent metabolomic successes have been based on only a fraction or two of the full spectrum of metabolites. Ongoing efforts to 
characterize the existing "unknowns" will soon enable more exhaustive investigations.

\section{Future Directions: Human Systems Integration}

As outlined above, each system level has potential to reveal insight to disease development and response to diet. Besides single SNP-, transcript-, protein-, and metabolite-trait testing, network analysis (knowledge-driven) or computational modeling of all system-level data-points (data-driven) also may be performed. Integrating system-level data from external resources is another feasible and highly efficient approach epidemiologists are taking to maximize "omic" data [126-128]. However, extrapolating results from an integrative analysis of potentially diverse datasets does not provide a complete understanding of the human system and its responses to diet as a whole. Intermediate molecular quantitative trait locus (iQTLs) analysis has been one advancement towards integrating largescale omic data $[22,129]$. In iQTL mapping, transcripts, proteins, metabolites, or other heritable physiological factors serve as traits for genetic association analysis, the rationale being that these intermediates (or endophenotypes) more closely underlie genetic risk than heterogeneous behavioral or disease phenotypes [129, 130].

The ideal system-wide study would have multi-omic data for an individual collected at multiple time points along with exposure details and longitudinal follow-up. Chen et al. $[131 \bullet \cdot]$ recently explored this concept of an "integrative personal omics profile" (iPOP) by combining several omicprofiles from a single individual during a 14-month period. iPOP revealed various health risks, including T2D and uncovered extensive, dynamic changes in diverse molecular components, and biological pathways across healthy and diseased conditions. This iPOP framework might easily be upscaled to a nutritional intervention study. The most ambitious systems epidemiology approach would apply this iPOP framework to a population-setting. Harnessing the resources of existing large prospective studies of lifestyle and chronic diseases, which have archived biological samples and repeated measures of diet and lifestyle, would be the most efficient approach to reaching this goal [1]. This strategy was recently applied to a subset of individuals participating in the Finnish population-based Dietary, Lifestyle, and Genetic determinants of Obesity and Metabolic syndrome (DILGOM) study [132] and preliminary cross-sectional analysis are promising. Network analysis of transcriptomic and metabolomic data available from 518 individuals identified genes from the lipid-leukocyte (LL) module as having a key role in more than 80 metabolites, including lipoprotein subclasses, lipids, and amino acids. Genomic variation was used to infer this module's reactivity to fatty acids and high/low/intermediate-density lipoprotein fractions. Parallel associations with plasma IL-
1 receptor antagonist, C-reactive protein, and adiponectin suggested the LL module as a possible link between inflammation, metabolism, and adiposity [132].

Although beyond the scope of the current paper, there are several important issues that still need to be resolved before considering system tools in the broader field of systems epidemiology. For example, a common goal in epidemiology is to relate a "usual" level of an exposure with the risk of disease [133] and an outstanding concern pertains to the fact that transcript, protein, and metabolite levels vary with time and recent environmental factors. Quantifying and identifying the source of this variation and the extent to which this variation impacts power for detecting associations warrants further study [134•]. How repeated measures may remedy this concern also is an open question. Another issue is that the multiple-testing problem is likely to be magnified in multi-omic studies, which will have significant impact on the power and data interpretation. Epidemiologists will need to be mindful of these and other limitations when designing and interpreting system-wide studies.

\section{Conclusions}

Nutritional systems epidemiology has potential to provide new insight into underlying mechanisms and ways to study the health effects of specific foods more comprehensively. Coincident with advancing nutrition research, it has incredible potential to finally realize the concept of personalized nutrition. Continued technological advances in sensitive high-throughput methods, enhanced bioinformatics and analytical tools, and reduced costs will enable more widespread use of these techniques in nutrition and epidemiological research. However, critical to the success of this approach is well-designed prospective cohort studies with very large size, long-term followup, high rates of follow-up, availability of archived biological samples, and detailed measures of diet and lifestyle. Our brief summary of selected studies across systems already yield impressive results and when merged with equivalent applications to T2D provide compelling evidence that the goal of personalized optimal nutrition for prevention and treatment of disease will become increasingly attainable by systems epidemiological approaches.

\section{Compliance with Ethics Guidelines}

Conflict of Interest Marilyn C. Cornelis declares that she has no conflict of interest relevant to this review.

Frank B. Hu declares that he has no conflict of interest relevant to this review.

Human and Animal Rights and Informed Consent This article does not contain any studies with human or animal subjects performed by any of the authors. 


\section{References}

Papers of particular interest published recently have been highlighted as:

- Of importance

-. Of major importance

1. Hu FB. Metabolic profiling of diabetes: from black-box epidemiology to systems epidemiology. Clin Chem. 2011;57(9):1224-6.

2. Haring R, Wallaschofski H: Diving through the "-omics": the case for deep phenotyping and systems epidemiology. Omics 2012.

3. Lund E, Dumeaux V. Systems epidemiology in cancer. Cancer Epidemiol Biomarkers Prev. 2008;17(11):2954-7.

4. Bictash M, Ebbels TM, Chan Q, et al. Opening up the "Black Box": metabolic phenotyping and metabolome-wide association studies in epidemiology. J Clin Epidemiol. 2010;63(9):970-9.

5. Keusch GT. What do -omics mean for the science and policy of the nutritional sciences? Am J Clin Nutr. 2006;83(2):520S-2.

6. • Morris AP, Voight BF, Teslovich TM, et al. Large-scale association analysis provides insights into the genetic architecture and pathophysiology of type 2 diabetes. Nat Genet. 2012;44(9):981-90. This article is the latest in a series of successful genome-wide association studies of type 2 diabetes that demonstrate the power of an agnostic system-wide approach to susceptibility loci discovery.

7. McCarthy MI. Genomics, type 2 diabetes, and obesity. N Engl J Med. 2010;363(24):2339-50.

8. Ericson U, Sonestedt E, Gullberg B, et al. High intakes of protein and processed meat associate with increased incidence of type 2 diabetes. Br J Nutr. 2013;109(6):1143-53.

9. Hu FB, Manson JE, Stampfer MJ, et al. Diet, lifestyle, and the risk of type 2 diabetes mellitus in women. N Engl J Med. 2001;345(11):790-7.

10. Djousse L, Gaziano JM, Buring JE, et al. Dietary omega-3 fatty acids and fish consumption and risk of type 2 diabetes. Am J Clin Nutr. 2011;93(1):143-50.

11. van Dam RM, Hu FB. Coffee consumption and risk of type 2 diabetes: a systematic review. JAMA. 2005;294(1):97-104.

12. Koppes LL, Dekker JM, Hendriks HF, et al. Moderate alcohol consumption lowers the risk of type 2 diabetes: a meta-analysis of prospective observational studies. Diabetes Care. 2005;28(3):719 25.

13. Jiang R, Manson JE, Meigs JB, et al. Body iron stores in relation to risk of type 2 diabetes in apparently healthy women. JAMA. 2004;291(6):711-7.

14. Nettleton JA, Hivert MF, Lemaitre RN, et al. Meta-analysis investigating associations between healthy diet and fasting glucose and insulin levels and modification by loci associated with glucose homeostasis in data from 15 cohorts. Am J Epidemiol. 2013;177(2):103-15.

15. • Cornelis MC, Hu FB. Gene-Environment Interactions in the Development of Type 2 Diabetes: Recent Progress and Continuing Challenges. Annu Rev Nutr. 2012;32:245-59. This article discusses recent progress, continuing challenges, evolving approaches, and recommendations for future efforts pertaining to studies of geneenvironment interactions of type 2 diabetes.

16. Vimaleswaran KS, Berry DJ, Lu C, et al. Causal relationship between obesity and vitamin D status: bi-directional Mendelian randomization analysis of multiple cohorts. PLoS Med. 2013;10(2):e1001383.

17. Franks PW, Pearson E, Florez JC. Gene-environment and genetreatment interactions in type 2 diabetes: progress, pitfalls, and prospects. Diabetes Care. 2013;36(5):1413-21.

18. •• Qi Q, Chu AY, Kang JH, et al. Sugar-sweetened beverages and genetic risk of obesity. N Engl J Med. 2012;367(15):1387-96. This article tests and validates an interaction between a genetic score of established obesity risk loci and sugar-sweetened beverages for risk of obesity.
19. • Herder C, Karakas M, Koenig W. Biomarkers for the prediction of type 2 diabetes and cardiovascular disease. Clin Pharmacol Ther. 2011;90(1):52-66. This article provides an exhaustive review of system-level studies for prediction of type 2 diabetes and cardiovascular disease.

20. Cornelis MC, Monda KL, Yu K, et al. Genome-wide metaanalysis identifies regions on 7p21 (AHR) and 15q24 (CYP1A2) as determinants of habitual caffeine consumption. PLoS Genet. 2011;7(4):e1002033.

21. Agrawal A, Freedman ND, Cheng YC, et al. Measuring alcohol consumption for genomic meta-analyses of alcohol intake: opportunities and challenges. Am J Clin Nutr. 2012;95(3):539-47.

22. Meng Q, Makinen VP, Luk H, et al. Systems Biology Approaches and Applications in Obesity, Diabetes, and Cardiovascular Diseases. Curr Cardiovas Risk Rep. 2013;7(1):73-83.

23. Afman LA, Muller M. Human nutrigenomics of gene regulation by dietary fatty acids. Prog Lipid Res. 2012;51(1):63-70.

24. Takamura T, Honda M, Sakai Y, et al. Gene expression profiles in peripheral blood mononuclear cells reflect the pathophysiology of type 2 diabetes. Biochem Biophys Res Commun. 2007;361(2):37984.

25. Zampetaki A, Kiechl S, Drozdov I, et al. Plasma microRNA profiling reveals loss of endothelial miR-126 and other microRNAs in type 2 diabetes. Circ Res. 2010;107(6):810-7.

26. Wang S, Aurora AB, Johnson BA, et al. The endothelial-specific microRNA miR-126 governs vascular integrity and angiogenesis. Dev Cell. 2008;15(2):261-71.

27. Camargo A, Ruano J, Fernandez JM, et al. Gene expression changes in mononuclear cells in patients with metabolic syndrome after acute intake of phenol-rich virgin olive oil. BMC Genomics. 2010;11:253.

28. Bouwens M, Grootte Bromhaar M, Jansen J, et al. Postprandial dietary lipid-specific effects on human peripheral blood mononuclear cell gene expression profiles. Am J Clin Nutr. 2010;91(1):208-17.

29. van Dijk SJ, Feskens EJ, Bos MB, et al. A saturated fatty acid-rich diet induces an obesity-linked proinflammatory gene expression profile in adipose tissue of subjects at risk of metabolic syndrome. Am J Clin Nutr. 2009;90(6):1656-64.

30. Bouwens M, van de Rest O, Dellschaft N, et al. Fish-oil supplementation induces antiinflammatory gene expression profiles in human blood mononuclear cells. Am J Clin Nutr. 2009;90(2):41524.

31. Kabir M, Skurnik G, Naour N, et al. Treatment for 2 mo with n 3 polyunsaturated fatty acids reduces adiposity and some atherogenic factors but does not improve insulin sensitivity in women with type 2 diabetes: a randomized controlled study. Am J Clin Nutr. 2007;86(6):1670-9.

32. Kallio P, Kolehmainen M, Laaksonen DE, et al. Dietary carbohydrate modification induces alterations in gene expression in abdominal subcutaneous adipose tissue in persons with the metabolic syndrome: the FUNGENUT Study. Am J Clin Nutr. 2007;85(5):1417-27.

33. Di Caro S, Tao H, Grillo A, et al. Effects of Lactobacillus GG on genes expression pattern in small bowel mucosa. Dig Liver Dis. 2005;37(5):320-9.

34. van Oostrom O, de Kleijn DP, Fledderus JO, et al. Folic acid supplementation normalizes the endothelial progenitor cell transcriptome of patients with type 1 diabetes: a case-control pilot study. Cardiovasc Diabetol. 2009;8:47.

35. Khymenets O, Fito M, Covas MI, et al. Mononuclear cell transcriptome response after sustained virgin olive oil consumption in humans: an exploratory nutrigenomics study. Omics. 2009;13(1):7-19.

36. Safdar A, Yardley NJ, Snow R, et al. Global and targeted gene expression and protein content in skeletal muscle of young men following short-term creatine monohydrate supplementation. Physiol Genomics. 2008;32(2):219-28. 
37. Tsavachidou D, McDonnell TJ, Wen S, et al. Selenium and vitamin $\mathrm{E}$ : cell type- and intervention-specific tissue effects in prostate cancer. J Natl Cancer Inst. 2009;101(5):306-20.

38. Linnane AW, Kopsidas G, Zhang C, et al. Cellular redox activity of coenzyme Q10: effect of CoQ10 supplementation on human skeletal muscle. Free Radic Res. 2002;36(4):445-53.

39. Niculescu MD, Pop EA, Fischer LM, et al. Dietary isoflavones differentially induce gene expression changes in lymphocytes from postmenopausal women who form equol as compared with those who do not. J Nutr Biochem. 2007;18(6):380-90.

40. Crujeiras AB, Parra D, Milagro FI, et al. Differential expression of oxidative stress and inflammation related genes in peripheral blood mononuclear cells in response to a low-calorie diet: a nutrigenomics study. Omics. 2008;12(4):251-61.

41. Dahlman I, Linder K, Arvidsson Nordstrom E, et al. Changes in adipose tissue gene expression with energy-restricted diets in obese women. Am J Clin Nutr. 2005;81(6):1275-85.

42. Ong KR, Sims AH, Harvie M, et al. Biomarkers of dietary energy restriction in women at increased risk of breast cancer. Canc Prev Res (Philadelphia, Pa). 2009;2(8):720-31.

43. Capel F, Viguerie N, Vega N, et al. Contribution of energy restriction and macronutrient composition to changes in adipose tissue gene expression during dietary weight-loss programs in obese women. J Clin Endocrinol Metab. 2008;93(11):4315-22.

44. van Erk MJ, Blom WA, van Ommen B, et al. High-protein and highcarbohydrate breakfasts differentially change the transcriptome of human blood cells. Am J Clin Nutr. 2006;84(5):1233-41.

45. Diamant M, Blaak EE, de Vos WM. Do nutrient-gut-microbiota interactions play a role in human obesity, insulin resistance and type 2 diabetes? Obes Rev. 2011;12(4):272-81.

46. Wu X, Ma C, Han L, et al. Molecular characterisation of the faecal microbiota in patients with type II diabetes. Curr Microbiol. 2010;61(1):69-78.

47. Kalliomaki M, Collado MC, Salminen S, et al. Early differences in fecal microbiota composition in children may predict overweight. Am J Clin Nutr. 2008;87(3):534-8.

48. Fukushima Y, Kasuga M, Nakao K, et al. Effects of coffee on inflammatory cytokine gene expression in mice fed high-fat diets. J Agric Food Chem. 2009;57(23):11100-5.

49. Schulze MB, Hoffmann K, Manson JE, et al. Dietary pattern, inflammation, and incidence of type 2 diabetes in women. Am J Clin Nutr. 2005;82(3):675-84. quiz 714-675.

50. - Chadt A, Yeo GS, Al-Hasani H. Nutrition-/diet-induced changes in gene expression in pancreatic beta-cells. Diabetes Obes Metab. 2012;14 Suppl 3:57-67. This article reviews the application of targeted and genome-wide approaches to diet-induced changes in gene expression in type 2 diabetes target tissue and supports the important utility of experimental studies to address scientific questions that cannot be feasibly answered by human studies.

51. Tyers M, Mann M. From genomics to proteomics. Nature. 2003;422(6928):193-7.

52. Anderson NL, Polanski M, Pieper R, et al. The human plasma proteome: a nonredundant list developed by combination of four separate sources. Mol Cell Proteomics. 2004;3(4):311-26.

53. Wittwer J, Rubio-Aliaga I, Hoeft B, et al. Nutrigenomics in human intervention studies: current status, lessons learned and future perspectives. Mol Nutr Food Res. 2011;55(3):341-58.

54. Considine RV, Sinha MK, Heiman ML, et al. Serum immunoreactiveleptin concentrations in normal-weight and obese humans. N Engl J Med. 1996;334(5):292-5.

55. Hotta K, Funahashi T, Arita Y, et al. Plasma concentrations of a novel, adipose-specific protein, adiponectin, in type 2 diabetic patients. Arterioscler Thromb Vasc Biol. 2000;20(6):1595-9.

56. Norata GD, Ongari M, Garlaschelli K, et al. Plasma resistin levels correlate with determinants of the metabolic syndrome. Eur J Endocrinol. 2007;156(2):279-84.
57. Vozarova B, Weyer C, Hanson K, et al. Circulating interleukin-6 in relation to adiposity, insulin action, and insulin secretion. Obes Res. 2001;9(7):414-7.

58. Sundsten T, Ortsater H. Proteomics in diabetes research. Mol Cell Endocrinol. 2009;297(1-2):93-103.

59. Jiang M, Jia L, Jiang W, et al. Protein disregulation in red blood cell membranes of type 2 diabetic patients. Biochem Biophys Res Commun. 2003;309(1):196-200.

60. Zhang R, Barker L, Pinchev D, et al. Mining biomarkers in human sera using proteomic tools. Proteomics. 2004;4(1):244-56.

61. Hwang $\mathrm{H}$, Bowen BP, Lefort N, et al. Proteomics analysis of human skeletal muscle reveals novel abnormalities in obesity and type 2 diabetes. Diabetes. 2010;59(1):33-42.

62. Boden G, Duan X, Homko C, et al. Increase in endoplasmic reticulum stress-related proteins and genes in adipose tissue of obese, insulin-resistant individuals. Diabetes. 2008;57(9):2438-44.

63. Fuchs D, Vafeiadou K, Hall WL, et al. Proteomic biomarkers of peripheral blood mononuclear cells obtained from postmenopausal women undergoing an intervention with soy isoflavones. Am J Clin Nutr. 2007;86(5):1369-75.

64. Fuchs D, Piller R, Linseisen J, et al. The human peripheral blood mononuclear cell proteome responds to a dietary flaxseedintervention and proteins identified suggest a protective effect in atherosclerosis. Proteomics. 2007;7(18):3278-88.

65. de Roos B, Geelen A, Ross K, et al. Identification of potential serum biomarkers of inflammation and lipid modulation that are altered by fish oil supplementation in healthy volunteers. Proteomics. 2008;8(10):1965-74.

66. Duthie SJ, Horgan G, de Roos B, et al. Blood folate status and expression of proteins involved in immune function, inflammation, and coagulation: biochemical and proteomic changes in the plasma of humans in response to long-term synthetic folic acid supplementation. J Proteome Res. 2010;9(4):1941-50.

67. Bakker GC, van Erk MJ, Pellis L, et al. An antiinflammatory dietary mix modulates inflammation and oxidative and metabolic stress in overweight men: a nutrigenomics approach. Am J Clin Nutr. 2010;91(4):1044-59.

68. Esposito K, Marfella R, Ciotola M, et al. Effect of a mediterraneanstyle diet on endothelial dysfunction and markers of vascular inflammation in the metabolic syndrome: a randomized trial. JAMA. 2004;292(12):1440-6.

69. Nettleton JA, Matijevic N, Follis JL, et al. Associations between dietary patterns and flow cytometry-measured biomarkers of inflammation and cellular activation in the Atherosclerosis Risk in Communities (ARIC) Carotid Artery MRI Study. Atherosclerosis. 2010;212(1):260-7.

70. Lopez-Garcia E, Schulze MB, Fung TT, et al. Major dietary patterns are related to plasma concentrations of markers of inflammation and endothelial dysfunction. Am J Clin Nutr. 2004;80(4):1029-35.

71. Garcia-Bailo B, Brenner DR, Nielsen D, et al. Dietary patterns and ethnicity are associated with distinct plasma proteomic groups. Am J Clin Nutr. 2012;95(2):352-61.

72. Norheim F, Gjelstad IM, Hjorth M, et al. Molecular nutrition research: the modern way of performing nutritional science. Nutr. 2012;4(12):1898-944.

73. Rezzi S, Ramadan Z, Fay LB, et al. Nutritional metabonomics: applications and perspectives. J Proteome Res. 2007;6(2):513-25.

74. Wishart DS. Human Metabolome Database: completing the 'human parts list'. Pharmacogenomics. 2007;8(7):683-6.

75. The Human Metabolome Project [www.metabolomics.ca].

76. Scalbert A, Brennan L, Fiehn O, et al. Mass-spectrometry-based metabolomics: limitations and recommendations for future progress with particular focus on nutrition research. Metabolomics. 2009;5(4):435-58.

77. • Koek MM, Jellema RH, van der Greef J, et al. Quantitative metabolomics based on gas chromatography mass spectrometry: 
status and perspectives. Metabolomics. 2011;7(3):307-28. This article provides technological and conceptual challenges as well as progress in the broader field of metabolomics.

78. Gall WE, Beebe K, Lawton KA, et al. alpha-hydroxybutyrate is an early biomarker of insulin resistance and glucose intolerance in a nondiabetic population. PLoS One. 2010;5(5):e10883.

79. Xu F, Tavintharan S, Sum CF et al.: Metabolic Signature Shift in Type 2 Diabetes Mellitus Revealed by Mass Spectrometry-based Metabolomics. J Clin Endocrinol Metab 2013.

80. Mihalik SJ, Goodpaster BH, Kelley DE, et al. Increased levels of plasma acylcarnitines in obesity and type 2 diabetes and identification of a marker of glucolipotoxicity. Obes (Silver Spring). 2010;18(9):1695-700.

81. Rhee EP, Cheng S, Larson MG, et al. Lipid profiling identifies a triacylglycerol signature of insulin resistance and improves diabetes prediction in humans. J Clin Invest. 2011;121(4):140211.

82. •• Floegel A, Stefan N, Yu Z, et al. Identification of serum metabolites associated with risk of type 2 diabetes using a targeted metabolomic approach. Diabetes. 2013;62(2):639-48. This article describes the largest prospective metabolomic study of type 2 diabetes conducted to date.

83. Suhre K, Meisinger C, Doring A, et al. Metabolic footprint of diabetes: a multiplatform metabolomics study in an epidemiological setting. PLoS One. 2010;5(11):e13953.

84. Wang TJ, Larson MG, Vasan RS, et al. Metabolite profiles and the risk of developing diabetes. Nat Med. 2011;17(4):448-53.

85. Wurtz P, Makinen VP, Soininen P et al.: Metabolic Signatures of Insulin Resistance in 7,098 Young Adults. Diabetes 2012.

86. Wurtz P, Tiainen M, Makinen VP, et al. Circulating metabolite predictors of glycemia in middle-aged men and women. Diabetes Care. 2012;35(8):1749-56.

87. Newgard CB, An J, Bain JR, et al. A branched-chain amino acidrelated metabolic signature that differentiates obese and lean humans and contributes to insulin resistance. Cell Metabol. 2009;9(4):31126.

88. Shah SH, Crosslin DR, Haynes CS, et al. Branched-chain amino acid levels are associated with improvement in insulin resistance with weight loss. Diabetologia. 2012;55(2):321-30.

89. Cheng S, Rhee EP, Larson MG et al.: Metabolite Profiling Identifies Pathways Associated with Metabolic Risk in Humans. Circulation 2012.

90. Huffman KM, Shah SH, Stevens RD, et al. Relationships between circulating metabolic intermediates and insulin action in overweight to obese, inactive men and women. Diabetes Care. 2009;32(9):1678-83.

91. Mihalik SJ, Michaliszyn SF, de Las Heras J, et al. Metabolomic Profiling of Fatty Acid and Amino Acid Metabolism in Youth With Obesity and Type 2 Diabetes: Evidence for enhanced mitochondrial oxidation. Diabetes Care. 2012;35(3):605-11.

92. Boyle KE, Canham JP, Consitt LA, et al. A high-fat diet elicits differential responses in genes coordinating oxidative metabolism in skeletal muscle of lean and obese individuals. J Clin Endocrinol Metab. 2011;96(3):775-81.

93. Shah SH, Svetkey LP, Newgard CB. Branching out for detection of type 2 diabetes. Cell Metabol. 2011;13(5):491-2.

94. Jakobsen LH, Kondrup J, Zellner M, et al. Effect of a high protein meat diet on muscle and cognitive functions: a randomised controlled dietary intervention trial in healthy men. Clin Nutr (Edinburgh, Scotland). 2010;30(3):303-11.

95. Koeth RA, Wang Z, Levison BS, et al. Intestinal microbiota metabolism of l-carnitine, a nutrient in red meat, promotes atherosclerosis. Nat Med. 2013;19(5):576-85.

96. •- Wang Z, Klipfell E, Bennett BJ, et al. Gut flora metabolism of phosphatidylcholine promotes cardiovascular disease. Nature. 2011;472(7341):57-63. This article presents the first of a series of investigations confirming an important role of gut flora metabolism (potentially modified by diet) in cardiovascular disease development.

97. Tang WH, Wang Z, Levison BS, et al. Intestinal microbial metabolism of phosphatidylcholine and cardiovascular risk. N Engl J Med. 2013;368(17):1575-84.

98. Bennett BJ, de Aguiar Vallim TQ, Wang Z, et al. Trimethylamine$\mathrm{N}$-oxide, a metabolite associated with atherosclerosis, exhibits complex genetic and dietary regulation. Cell Metabol. 2013;17(1):49 60.

99. Pellis L, van Erk MJ, van Ommen B, et al. Plasma metabolomics and proteomics profiling after a postprandial challenge reveal subtle diet effects on human metabolic status. Metabolomics. 2012;8(2):347-59.

100. Lankinen M, Schwab U, Gopalacharyulu PV, et al. Dietary carbohydrate modification alters serum metabolic profiles in individuals with the metabolic syndrome. Nutr Metab Cardiovasc Dis. 2010;20(4):249-57.

101. • Krug S, Kastenmuller G, Stuckler F et al.: The dynamic range of the human metabolome revealed by challenges. Faseb J 2012. This article presents important insight to the potential application of metabolomics for nutrition research in a clinical and population setting.

102. Altmaier E, Kastenmuller G, Romisch-Margl W, et al. Questionnairebased self-reported nutrition habits associate with serum metabolism as revealed by quantitative targeted metabolomics. Eur J Epidemiol. 2011;26(2):145-56.

103. Solanky KS, Bailey NJ, Beckwith-Hall BM, et al. Biofluid $1 \mathrm{H}$ NMR-based metabonomic techniques in nutrition research - metabolic effects of dietary isoflavones in humans. J Nutr Biochem. 2005;16(4):236-44.

104. Stella C, Beckwith-Hall B, Cloarec O, et al. Susceptibility of human metabolic phenotypes to dietary modulation. J Proteome Res. 2006;5(10):2780-8.

105. Walsh MC, Brennan L, Pujos-Guillot E, et al. Influence of acute phytochemical intake on human urinary metabolomic profiles. Am J Clin Nutr. 2007;86(6):1687-93.

106. Schwab U, Seppanen-Laakso T, Yetukuri L, et al. Triacylglycerol fatty acid composition in diet-induced weight loss in subjects with abnormal glucose metabolism-the GENOBIN study. PLoS One. 2008;3(7):e2630.

107. Chorell E, Moritz T, Branth S, et al. Predictive metabolomics evaluation of nutrition-modulated metabolic stress responses in human blood serum during the early recovery phase of strenuous physical exercise. J Proteome Res. 2009;8(6):2966-77.

108. Redeuil K, Smarrito-Menozzi C, Guy P et al.: Identification of novel circulating coffee metabolites in human plasma by liquid chromatography-mass spectrometry. J Chromatogr A 2011.

109. Nagy K, Redeuil K, Williamson G, et al. First identification of dimethoxycinnamic acids in human plasma after coffee intake by liquid chromatography-mass spectrometry. J Chromatogr A. 2011;1218(3):491-7.

110. Stalmach A, Mullen W, Barron D, et al. Metabolite profiling of hydroxycinnamate derivatives in plasma and urine after the ingestion of coffee by humans: identification of biomarkers of coffee consumption. Drug Metab Dispos. 2009;37(8):1749-58.

111. Kempf K, Herder C, Erlund I, et al. Effects of coffee consumption on subclinical inflammation and other risk factors for type 2 diabetes: a clinical trial. Am J Clin Nutr. 2010;91(4):950-7.

112. Daykin CA, Van Duynhoven JP, Groenewegen A, et al. Nuclear magnetic resonance spectroscopic based studies of the metabolism of black tea polyphenols in humans. J Agric Food Chem. 2005;53(5):1428-34.

113. van Velzen EJ, Westerhuis JA, van Duynhoven JP, et al. Phenotyping tea consumers by nutrikinetic analysis of polyphenolic end-metabolites. J Proteome Res. 2009;8(7):3317-30.

114. Martin FP, Rezzi S, Pere-Trepat E, et al. Metabolic effects of dark chocolate consumption on energy, gut microbiota, and 
stress-related metabolism in free-living subjects. J Proteome Res. 2009;8(12):5568-79.

115. Llorach R, Urpi-Sarda M, Tulipani S et al. : Metabolomic fingerprint in patients at high risk of cardiovascular disease by cocoa intervention. Mol Nutr Food Res 2013.

116. Tulipani S, Llorach R, Jauregui O, et al. Metabolomics unveils urinary changes in subjects with metabolic syndrome following 12-week nut consumption. J Proteome Res. 2011;10(11):5047-58.

117. Johansson-Persson A, Barri T, Ulmius M, et al. LC-QTOF/MS metabolomic profiles in human plasma after a 5-week high dietary fiber intake. Anal Bioanal Chem. 2013;405(14):4799-809.

118. McCombie G, Browning LM, Titman CM, et al. omega-3 oil intake during weight loss in obese women results in remodelling of plasma triglyceride and fatty acids. Metabolomics. 2009;5(3):363-74.

119. Altmaier E, Kastenmuller G, Romisch-Margl W, et al. Variation in the human lipidome associated with coffee consumption as revealed by quantitative targeted metabolomics. Mol Nutr Food Res. 2009;53(11):1357-65.

120. Adams SH, Hoppel CL, Lok KH, et al. Plasma acylcarnitine profiles suggest incomplete long-chain fatty acid beta-oxidation and altered tricarboxylic acid cycle activity in type 2 diabetic African-American women. J Nutr. 2009;139(6):1073-81.

121. Fiehn O, Garvey WT, Newman JW, et al. Plasma metabolomic profiles reflective of glucose homeostasis in non-diabetic and type 2 diabetic obese African-American women. PLoS One. 2010;5(12):e15234.

122. Kim JY, Park JY, Kim OY, et al. Metabolic profiling of plasma in overweight/obese and lean men using ultra performance liquid chromatography and Q-TOF mass spectrometry (UPLC-Q-TOF MS). J Proteome Res. 2010;9(9):4368-75.

123. Menni C, Zhai G, Macgregor A, et al. Targeted metabolomics profiles are strongly correlated with nutritional patterns in women. Metabolomics. 2013;9(2):506-14.

124. - Heinzmann SS, Merrifield CA, Rezzi S, et al. Stability and robustness of human metabolic phenotypes in response to sequential food challenges. J Proteome Res. 2012;11(2):643-55. This article presents important insight to the potential application of metabolomics for nutrition research in a clinical and population setting.

125. Demirkan A, van Duijn CM, Ugocsai P, et al. Genome-wide association study identifies novel loci associated with circulating phospho- and sphingolipid concentrations. PLoS Genet. 2012;8(2):e1002490.

126. Small KS, Hedman AK, Grundberg E, et al. Identification of an imprinted master trans regulator at the KLF14 locus related to multiple metabolic phenotypes. Nat Genet. 2011;43(6):561-4.

127. Zhong H, Yang X, Kaplan LM, et al. Integrating pathway analysis and genetics of gene expression for genome-wide association studies. Am J Hum Genet. 2010;86(4):581-91.

128. Greenawalt DM, Sieberts SK, Cornelis MC, et al. Integrating genetic association, genetics of gene expression, and single nucleotide polymorphism set analysis to identify susceptibility Loci for type 2 diabetes mellitus. Am J Epidemiol. 2012;176(5):423-30.

129. Yang $X$. Use of functional genomics to identify candidate genes underlying human genetic association studies of vascular diseases. Arterioscler Thromb Vasc Biol. 2012;32(2):216-22.

130. Robinette SL, Holmes E, Nicholson JK, et al. Genetic determinants of metabolism in health and disease: from biochemical genetics to genome-wide associations. Genome Med. 2012;4(4):30.

131. • Chen R, Mias GI, Li-Pook-Than J, et al. Personal omics profiling reveals dynamic molecular and medical phenotypes. Cell. 2012;148(6):1293-307. This article features the first "integrative personal omics profile" (iPOP) by combining several omic-profiles from a single individual over a 14-month period.

132. Inouye M, Kettunen J, Soininen P, et al. Metabonomic, transcriptomic, and genomic variation of a population cohort. Mol Syst Biol. 2010;6:441.
133. Dodd KW, Guenther PM, Freedman LS, et al. Statistical methods for estimating usual intake of nutrients and foods: a review of the theory. J Am Diet Assoc. 2006;106(10):1640-50.

134. - Sampson JN, Boca SM, Shu XO, et al. Metabolomics in epidemiology: sources of variability in metabolite measurements and implications. Cancer Epidemiol Biomarkers Prev. 2013;22(4):631-40. This article discusses important limitations of metabolomics applied to a population setting .

135. Kettunen J, Tukiainen T, Sarin AP, et al. Genome-wide association study identifies multiple loci influencing human serum metabolite levels. Nat Genet. 2012;44(3):269-76.

136. Xie W, Wood AR, Lyssenko V, et al. Genetic variants associated with glycine metabolism and their role in insulin sensitivity and type 2 diabetes. Diabetes. 2013;62(6):2141-50.

137. Ferrucci L, Perry JR, Matteini A, et al. Common variation in the beta-carotene 15,15'-monooxygenase 1 gene affects circulating levels of carotenoids: a genome-wide association study. Am J Hum Genet. 2009;84(2):123-33.

138. Kapur K, Johnson T, Beckmann ND, et al. Genome-wide metaanalysis for serum calcium identifies significantly associated SNPs near the calcium-sensing receptor (CASR) gene. PLoS Genet. 2010;6(7):e1001035.

139. O'Seaghdha CM, Yang Q, Glazer NL, et al. Common variants in the calcium-sensing receptor gene are associated with total serum calcium levels. Hum Mol Genet. 2010;19(21):4296-303.

140. Kutalik Z, Benyamin B, Bergmann S, et al. Genome-wide association study identifies two loci strongly affecting transferrin glycosylation. Hum Mol Genet. 2011;20(18):3710-7.

141. McLaren CE, Garner CP, Constantine CC, et al. Genome-wide association study identifies genetic loci associated with iron deficiency. PLoS One. 2011;6(3):e17390.

142. Benyamin B, McRae AF, Zhu G, et al. Variants in TF and HFE explain approximately $40 \%$ of genetic variation in serum-transferrin levels. Am J Hum Genet. 2009;84(1):60-5.

143. Pichler I, Minelli C, Sanna S, et al. Identification of a common variant in the TFR2 gene implicated in the physiological regulation of serum iron levels. Hum Mol Genet. 2011;20(6):123240.

144. Benyamin B, Ferreira MA, Willemsen G, et al. Common variants in TMPRSS6 are associated with iron status and erythrocyte volume. Nat Genet. 2009;41(11):1173-5.

145. Tanaka T, Roy CN, Yao W, et al. A genome-wide association analysis of serum iron concentrations. Blood. 2010;115(1):94-6.

146. Oexle K, Ried JS, Hicks AA, et al. Novel association to the proprotein convertase PCSK 7 gene locus revealed by analysing soluble transferrin receptor (sTfR) levels. Hum Mol Genet. 2011;20(5):1042-7.

147. Meyer TE, Verwoert GC, Hwang SJ et al.: Genome-wide association studies of serum magnesium, potassium, and sodium concentrations identify six Loci influencing serum magnesium levels. PLoS Genet 2010; 6(8).

148. Mondul AM, Yu K, Wheeler W, et al. Genome-wide association study of circulating retinol levels. Hum Mol Genet. 2011;20(23):4724-31.

149. Hazra A, Kraft P, Selhub J, et al. Common variants of FUT2 are associated with plasma vitamin B12 levels. Nat Genet. 2008;40(10):1160-2.

150. Tanaka T, Scheet P, Giusti B, et al. Genome-wide association study of vitamin B6, vitamin B12, folate, and homocysteine blood concentrations. Am J Hum Genet. 2009;84(4):477-82.

151. Lin X, Lu D, Gao Y, et al. Genome-wide association study identifies novel loci associated with serum level of vitamin B12 in Chinese men. Hum Mol Genet. 2012;21(11):2610-7.

152. Ahn J, Yu K, Stolzenberg-Solomon R, et al. Genome-wide association study of circulating vitamin D levels. Hum Mol Genet. 2010;19(13):2739-45. 
153. Wang TJ, Zhang F, Richards JB, et al. Common genetic determinants of vitamin D insufficiency: a genome-wide association study. Lancet. 2010;376(9736):180-8.

154. Lasky-Su J, Lange N, Brehm JM, et al. Genome-wide association analysis of circulating vitamin D levels in children with asthma. Hum Genet. 2012;131(9):1495-505.

155. Major JM, Yu K, Chung CC, et al. Genome-wide association study identifies three common variants associated with serologic response to vitamin E supplementation in men. J Nutr. 2012;142(5):866-71.

156. Major JM, Yu K, Wheeler W, et al. Genome-wide association study identifies common variants associated with circulating vitamin $\mathrm{E}$ levels. Hum Mol Genet. 2011;20(19):3876-83.

157. Baik I, Cho NH, Kim SH, et al. Genome-wide association studies identify genetic loci related to alcohol consumption in Korean men. Am J Clin Nutr. 2011;93(4):809-16.

158. Takeuchi F, Isono M, Nabika T, et al. Confirmation of ALDH2 as a Major locus of drinking behavior and of its variants regulating multiple metabolic phenotypes in a Japanese population. Circ J. 2011;75(4):911-8.
159. Yang $\mathrm{X}, \mathrm{Lu} \mathrm{X}$, Wang $\mathrm{L}$, et al. Common variants at $12 \mathrm{q} 24$ are associated with drinking behavior in Han Chinese. Am J Clin Nutr. 2013;97(3):545-51.

160. Schumann G, Coin LJ, Lourdusamy A, et al. Genome-wide association and genetic functional studies identify autism susceptibility candidate 2 gene (AUTS2) in the regulation of alcohol consumption. Proc Natl Acad Sci U S A. 2011;108(17):7119-24.

161. Sulem P, Gudbjartsson DF, Geller F et al.: Sequence variants at CYP1A1-CYP1A2 and AHR associate with coffee consumption. Hum Mol Genet 2011.

162. Amin N, Byrne E, Johnson J et al.: Genome-wide association analysis of coffee drinking suggests association with CYP1A1/ CYP1A2 and NRCAM. Molecular psychiatry 2011.

163. Chu AY, Workalemahu T, Paynter NP et al. : Novel locus including FGF21 is associated with dietary macronutrient intake. Hum Mol Genet 2013.

164. Hindorff LA, Sethupathy P, Junkins HA, et al. Potential etiologic and functional implications of genome-wide association loci for human diseases and traits. Proc Natl Acad Sci U S A. 2009;106(23):9362-7. 